\title{
DETECTION OF SCALE INSECTS (HEMIPTERA: DIASPIDIDAE) IN 2004
}

\author{
K.L. PAICE ${ }^{1}$, J.E. RICHMOND ${ }^{1}$, S.J. BENNETT ${ }^{1}$, H.G. PEARSON ${ }^{1}$ \\ and G.S.C. GILL ${ }^{2}$ \\ ${ }^{1}$ Biosecurity New Zealand, MAF, PO Box 2095, Auckland \\ ${ }^{2}$ Biosecurity New Zealand, MAF, PO Box 2526, Wellington \\ Corresponding author: Kerry.Paice@maf.govt.nz
}

In 2004, the Incursion and Diagnostic Centre, Biosecurity New Zealand, responded to three new-to-New Zealand scale insects: Chrysomphalus aonidum (Florida red scale, FRS), Furchadaspis zamiae (zamia scale) and Aulacaspis yasumatsui (cycad scale). FRS was detected in heated glasshouses in Auckland and traced to imported Dracaena plants. Surveys carried out in response to FRS resulted in the detection of zamia and cycad scales both on Cycas revoluta. FRS and cycad scale have not been detected alive outside a heated glasshouse environment. FRS has been the subject of an eradication programme, while all plants associated with cycad scale have been destroyed. Biosecurity New Zealand is continuing to monitor the efficacy of the FRS eradication programme. Live zamia scale has been detected on cycads outside of a heated glasshouse environment in Hamilton, Coromandel, Auckland and Northland. The scale has been observed to be parasitised by the established wasp, Encarsia citrina. All these scale insects are New Organisms under the Hazardous Substances and New Organisms Act (1996), while FRS and cycad scale remain unwanted organisms under the Biosecurity Act (1993).

\section{THE VARIETY OF INSECTS CAUGHT IN A 7.5 M HIGH SUCTION TRAP}

\author{
D.E. JAMES and D.A.J. TEULON \\ Crop \& Food Research, Private Bag 4704, Christchurch, New Zealand \\ Corresponding author: jamesd@crop.cri.nz
}

Suction traps are widely used to monitor insect flights, most commonly of aphids (Hemiptera). To determine the usefulness of these suction traps for monitoring other insects, samples from a 7.5 m high suction trap at Lincoln, Canterbury, New Zealand, were identified. Four samples, representative of each season during 2003-04, were collected and their contents sorted into taxonomic orders. Up to seven orders were present in the samples - Coleoptera, Diptera, Hemiptera, Hymenoptera, Lepidoptera, Neuroptera and Thysanoptera. In spring, autumn and winter the predominant order caught in the suction trap was Diptera, comprising 89, 72 and $98 \%$ (respectively) of the total insects caught. At these times the next most common orders were Hemiptera (mainly aphids) and Thysanoptera. The remaining orders, when present, occurred in very low numbers. The greatest diversity of insects was present in summer with higher numbers of all seven insect orders. The summer sample also consisted largely of one order, but Thysanoptera was the dominant order (78\% of total insects caught) rather than Diptera. For this sample, Diptera comprised less than $2 \%$ of total insects caught. 